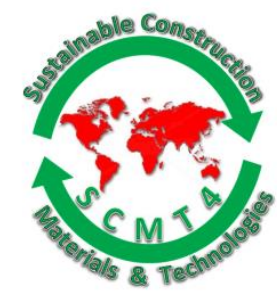

SCMT4

Las Vegas, USA, August 7-11, 2016

\title{
Steam Curing Effect on the Properties of Fly Ash High Performance Recycled Aggregates Concrete
}

\author{
Andreu Gonzalez-Corominas ${ }^{1 \mathrm{a}}$, and Miren Etxeberria ${ }^{1 \mathrm{~b} *}$ \\ ${ }^{1}$ Department of Construction Engineering, Polytechnic University of Catalonia, Jordi Girona, 1-3 B1 \\ building, Barcelona 08034, Spain. \\ ${ }^{1 a}$ Dr. Eng. Associate professor, Department of Construction Engineering, Polytechnic University of \\ Catalonia, Jordi Girona, 1-3 B1 building, Barcelona 08034, Spain, telephone: +34934011788, Fax: \\ +34934017262, ${ }^{1 b}$ Email: <miren.etxeberria@upc.edu>.
}

\begin{abstract}
The aim of this study is to encourage the use of Recycled Concrete Aggregate (RCA) in High Performance Concrete (HPC) with fly ash. Three types of coarse RCA sourced from medium to high strength concretes were employed in $100 \%$ replacement. In order to boost their mechanical performance at early age, steam curing was assessed. The physical, mechanical and durability properties of Recycled Aggregate Concretes (RAC) were compared to those from Natural Aggregate Concrete (NAC). According to the results, natural aggregates could be completely replaced by RCA if they are sourced from similar parent HPC. Lower quality RCAs decreased the mechanical and durability behavior of HPC. However, the properties of RAC had higher long-term improvements than those from NAC due to the influence of fly ash. Despite steam curing produced higher early-age compressive strength, it had longterm negative effects. Nevertheless, RACs were less affected by long term effects of steam curing.
\end{abstract}

\section{INTRODUCTION}

Construction is the economic sector that generates the highest amount of waste (Eurostat 2012). It is also estimated that the cement industry is responsible for $5 \%$ of $\mathrm{CO}_{2}$ total emissions. The use of fly ash in recycled aggregate concretes has been developed in this study in order to reduce the use of natural aggregate, decrease the Construction and Demolition Waste (CDW) disposal on landfills and moderate the cement consumption.

Over the last two decades, many studies have been published (Silva et al. 2014; Etxeberria et al. 2007) regarding the recycled aggregates properties and its influence on the concrete performance in comparison with natural aggregates. Recycled aggregates have higher porosity, water absorption capacity and contaminants content than natural aggregates. Also recycled aggregates show lower density, abrasion resistance and impact resistance than natural aggregates which may reduce the mechanical behavior of the concrete. 
In this study, the replacement of natural aggregates was limited to Recycled Concrete Aggregate (RCA) which was exclusively sourced from well-known structural concrete. Most studies concerning the use of RCA have been focused on the production of low and medium strength concretes (up to 50-60 MPa) (Etxeberria et al. 2007; Kou et al. 2008). RCA causes negative influence on some fresh and hardened concrete properties. The use of appropriate mix design methods and the addition of mineral admixtures can mitigate such negative influence (Kou \& Poon 2012; Tam et al. 2005). Some studies raised the use of RCA to produce High Performance Concrete (HPC). Ajdukiewicz and Kliszczewicz (Ajdukiewicz \& Kliszczewicz 2002) and Gonzalez-Corominas and Etxeberria (Gonzalez-Corominas \& Etxeberria 2014) found successful results on HPC using RCA sourced from moderate and high strength concretes. Both studies concluded that the quality of the original concrete has significant influence on mechanical properties of recycled aggregate concrete.

The use of fly ash in Recycled Aggregate Concretes (RAC) has been widely accepted in recent years (Kou et al. 2008; Limbachiya et al. 2011). Fly ash represents a beneficial mineral admixture for concrete which creates a denser cementitious matrix due to the formation of new CSH gel by the pozzolanic reactions. The RCAs enhance the binding effects of pozzolanic mineral admixtures by providing higher Portlandite amounts, especially those RCAs sourced from HPC (Ajdukiewicz \& Kliszczewicz 2002). In low water/binder ratio concretes, the most common replacement ratios of fly ash are 25-30\% (Poon et al. 2000; Ba et al. 2011). In general, the long term mechanical and durability properties of concretes containing fly ash are higher than those from ordinary Portland cement concretes. However, the early age properties are lower due to longer hardening times and extended binder hydrations.

Implementing steam curing process on concretes containing fly ash may increase the early-age compressive strength which could ease the achievement of the requirements for precast and prestressed concretes (Yazic1 et al. 2005). The steam curing produces faster binder hydration and increases the formation of CSH gel (Baoju et al. 2001). However, steam curing also increases the proportion of large pores. Inadequate steam curing regimes can lead concrete to detrimental changes in their porous network which can significantly reduce the mechanical and durability behavior, especially over the long term (Ba et al. 2011).

In this research work, the effects of steam curing on the mechanical and durability properties of fly ash HPC produced with recycled concrete aggregates were analyzed. The influence of the quality RCA on the steam cured HPC was also assessed. Three different qualities of parent concrete $(40,60$ and $100 \mathrm{MPa}$ of characteristic compressive strength) were used to replace $100 \%$ of the natural coarse aggregates. After concrete casting, the specimens of each type of concrete were exposed for the first 24 hours to two different initial curing regimes, conventional curing and steam curing.

\section{EXPERIMENTAL INVESTIGATION}

Materials. The concrete mixtures were produced using Portland cement (CEM I 52.5R) of 3.15 $\mathrm{g} / \mathrm{cm}^{3}$ of density and a specific surface of $4947.8 \mathrm{~cm}^{2} / \mathrm{g}$. Fly ash was used as supplementary material at $30 \%$ replacement by weight of Portland cement. Fly ash had a density of $2.32 \mathrm{~g} / \mathrm{cm}^{3}$ and a specific surface area of $3360.0 \mathrm{~cm}^{2} / \mathrm{g}$. The chemical compositions of both binders are shown in Table 1.

Table 1. Chemical composition of binders

\begin{tabular}{|l|l|l|l|l|l|l|l|l|l|l|}
\hline Chemical composition (\%) & $\mathrm{SiO}_{2}$ & $\mathrm{Fe}_{2} \mathrm{O}_{3}$ & $\mathrm{Al}_{2} \mathrm{O}_{3}$ & $\mathrm{CaO}$ & $\mathrm{MgO}$ & $\mathrm{K}_{2} \mathrm{O}$ & $\mathrm{Na}_{2} \mathrm{O}$ & $\mathrm{MnO}$ & $\mathrm{TiO}_{2}$ & $\mathrm{LOI}$ \\
\hline Portland Cement & 21.91 & 3.57 & 4.67 & 64.98 & 1.45 & 0.57 & 0.18 & 0.18 & 0.12 & 1.05 \\
\hline Fly ash & 55.46 & 26.94 & 5.86 & 5.70 & 1.50 & 1.51 & 1.41 & 0.83 & 0.62 & 3.70 \\
\hline
\end{tabular}


The admixture added to the concrete mixture was a high performance superplasticizer based on polycarboxylate ethers (PCE). This admixture was used in a proportion of $1 \%$ of the binder weight. The slump cone test results were found between $0-20 \mathrm{~mm}$ for all concrete mixtures.

All concrete mixtures were produced using two types of river sand, with particle size fraction of 0-2mm and $0-4 \mathrm{~mm}$. The Natural Aggregate Concrete (NAC) was produced using two coarse aggregates: crushed dolomite $(4-10 \mathrm{~mm})$ and river gravel $(4-11 \mathrm{~mm})$. The recycled coarse aggregates $(4-10 \mathrm{~mm})$ were sourced from three different parent concretes which had characteristic compressive strengths of 100, 60 and 40 $\mathrm{MPa}$. The physical properties of the aggregates are given in Table 2.

Table 2. Physical and mechanical properties of fine and coarse aggregate

\begin{tabular}{|c|c|c|c|c|c|c|}
\hline $\begin{array}{c}\text { Natural and } \\
\text { recycled } \\
\text { aggregates }\end{array}$ & $\begin{array}{c}\text { Oven-dried } \\
\text { particle } \\
\text { density } \\
\left(\mathrm{kg} / \mathrm{dm}^{3}\right)\end{array}$ & $\begin{array}{c}\text { Water } \\
\text { absorption } \\
(\%)\end{array}$ & $\begin{array}{c}\text { Flakiness } \\
\text { index (\%) }\end{array}$ & $\begin{array}{c}\text { Crushing } \\
\text { value (\%) }\end{array}$ & $\begin{array}{c}\text { LA Index } \\
(\%)\end{array}$ & $\begin{array}{c}\text { Assessment } \\
\text { of fines. Sand } \\
\text { equivalent } \\
\text { test (\%) }\end{array}$ \\
\hline Sand 0-2 mm & 2.57 & 1.93 & - & - & - & 75.00 \\
\hline Sand 0-4 mm & 2.50 & 1.02 & - & - & - & 87.88 \\
\hline River Gravel & 2.61 & 1.29 & 17.71 & 18.92 & 19.61 & - \\
\hline Dolomitic CA & 2.68 & 2.13 & 7.81 & 20.15 & 24.77 & - \\
\hline RCA 100MPa & 2.47 & 3.74 & 16.53 & 22.59 & 24.01 & - \\
\hline RCA 60MPa & 2.39 & 4.90 & 13.57 & 23.36 & 25.24 & - \\
\hline RCA 40MPa & 2.30 & 5.91 & 9.59 & 25.55 & 24.31 & - \\
\hline
\end{tabular}

Mixture proportions. The proportioning of concretes is detailed in Table 3. The concretes mixtures were referenced as NAC for natural aggregates concrete and R100, R60 and R40 for recycled aggregates concretes (according to the compressive strength of the parent concrete). $100 \%$ of the coarse natural aggregates were replaced (keeping constant their volume) by the coarse recycled aggregates. The fine natural aggregates volume was maintained in all the mixtures. SC is used to indicate those concretes which underwent the steam curing regime.

Table 3. Proportioning of concrete mixtures

\begin{tabular}{|l|l|l|l|l|l|l|l|l|}
\hline $\begin{array}{l}\text { Mix } \\
\text { notation }\end{array}$ & $\begin{array}{l}\text { Cement } \\
(\mathrm{kg})\end{array}$ & $\begin{array}{l}\text { Fly } \\
\text { Ash } \\
(\mathrm{kg})\end{array}$ & $\begin{array}{l}\text { River Sand } \\
0-2 \mathrm{~mm} \\
(\mathrm{~kg})\end{array}$ & $\begin{array}{l}\text { River Sand } \\
0-4 \mathrm{~mm} \\
(\mathrm{~kg})\end{array}$ & $\begin{array}{l}\text { River } \\
\text { Gravel } \\
(\mathrm{kg})\end{array}$ & $\begin{array}{l}\text { Dolomitic } \\
\text { Gravel } \\
(\mathrm{kg})\end{array}$ & $\begin{array}{l}\text { RA } \\
(\mathrm{kg})\end{array}$ & $\begin{array}{l}\text { Effectiv } \\
\text { e W/B }\end{array}$ \\
\hline NAC & 266 & 114 & 182.5 & 711.8 & 302.1 & 784.5 & --- & 0.29 \\
\hline R100 & 266 & 114 & 182.5 & 711.8 & - & - & 1010.2 & 0.29 \\
\hline R60 & 266 & 114 & 182.5 & 711.8 & - & - & 975.1 & 0.29 \\
\hline R40 & 266 & 114 & 182.5 & 711.8 & - & - & 938.8 & 0.29 \\
\hline
\end{tabular}

RCA were used in high moisture state (80-90\% of SSD) to avoid workability reductions due to its high water absorption capacity (Poon, Shui, Lam, et al. 2004). The effective water-cement ratio obtained from NAC (0.29) was kept constant in all RAC mixes. According to Neville (Neville 1995), the effective water-cement ratio is the amount of water in concrete, which is contained outside the aggregates, by the cement weight.

Curing procedures. The concretes were subjected to two curing processes, exposing all concrete mixtures to humidity room and to steam curing tank. The specimens which underwent conventional curing were kept in the laboratory environment $\left(18-24^{\circ} \mathrm{C}\right)$ covered with wet burlaps and plastic tops for a period of 24 hours. Immediately after casting, the steam-cured concrete specimens were subjected to a 
steam bath for 24 hours. The steam curing cycle followed the procedure defined by Poon and Kou (Kou et al. 2004). After the initial 24-hour period, all the specimens were demolded and stored in a standard curing room $\left(25^{\circ} \mathrm{C}\right.$ and $95 \%$ of humidity) until the testing ages were reached.

\section{Tests of hardened properties of concrete}

The compressive strength was measured at the ages of 1, 28 and 90 days following the UNE-EN 123903:2009 using 3 cube specimens of $100 \mathrm{~mm}$. The splitting tensile strength test was carried out according to UNE-EN 12390-6:2010 on three cylindrical specimens of $200 \times 100 \varnothing \mathrm{mm}$ at 28 days. The testing of porosity and pore structure was performed by Mercury Intrusion Porosimetry (MIP) with a 'Micromeritics Poresizer 9320' mercury intrusion porosimeter according to BS7591 Part 1 on small concrete pieces, weighing approximately $5.5 \mathrm{~g}$ at ages of 1,28 and 90 days. The capillary water absorption was tested at 28 days and 180 days of curing using 100x100x100 mm cubic specimens according to ISO 15148:2002. The resistance to chloride-ion penetrability was determined in accordance with ASTM C1202 (2012) using a $50 \times 100 \varnothing \mathrm{mm}$ concrete discs cut from the middle of $200 \times 100 \emptyset \mathrm{mm}$ concrete specimens at the ages of 28 and 180 days. In all tests, the final results were the average of three specimens for each concrete mixture.

\section{RESULTS AND DISCUSSIONS}

Compressive strength. The results from compressive strength at the ages of 1,28 and 180 days are presented in Table 4. Only the NAC and R100 concretes produced using conventional curing process achieved the minimum 1-day compressive strength in order to be used as HPC in prestressed concrete elements, designated as $50 \mathrm{MPa}$ (ADIF 2009; Ramezanianpour et al. 2013). The steam curing process permitted all concrete mixtures to fulfill that requirement. The highest results were obtained by the concretes containing RCA100 for both curing methods.

\section{Table 4. Results from the mechanical properties of concretes.}

\begin{tabular}{|l|c|c|c|c|}
\hline \multirow{2}{*}{ Mix notation } & \multicolumn{3}{|c|}{ Compressive strength (MPa) } & Splitting Tensile Strength (MPa) \\
\cline { 2 - 5 } & 1 day & $\mathbf{2 8}$ days & $\mathbf{9 0}$ days & 28 days \\
\hline NAC & 54.11 & 87.75 & 102.84 & 4.71 \\
\hline R100 & 56.81 & 91.61 & 110.88 & 4.78 \\
\hline R60 & 46.88 & 84.06 & 104.16 & 4.47 \\
\hline R40 & 44.23 & 76.90 & 88.18 & 3.95 \\
\hline \hline NAC-SC & 65.42 & 86.59 & 98.05 & 4.60 \\
\hline R100-SC & 66.18 & 83.69 & 99.62 & 4.97 \\
\hline R60-SC & 63.03 & 82.98 & 93.87 & 4.58 \\
\hline R40-SC & 52.44 & 75.63 & 83.18 & 4.07 \\
\hline
\end{tabular}

The use of RCA100 improved the compressive strength results from NAC at nearly all testing ages for conventional and steam curing. The concretes produced with RCA60 had similar or slightly lower compressive strength than NAC which was aligned with the results from Ajdukiewicz \& Kliszczewicz (Ajdukiewicz \& Kliszczewicz 2002). A severe decrease on the RCA quality caused notable reductions on compressive strength, the compressive strengths from concretes with RCA40 were, on average, 15 and $16 \%$ lower than those from NAC for conventional and steam curing, respectively, due to the low quality of the adhered mortar in comparison to the new cement paste. Nonetheless, it should be noted that the RACs had higher compressive strength gain up to 90 days than NAC due to the enhancement of pozzolanic reactivity from fly ash by the RCA content (Kou et al. 2008).

The steam-cured concretes showed 4-15\% higher 1-day compressive strength than their conventional- 
cured counterparts due to the acceleration of the CSH gel formation. For a given quality of RCA, steamcured concretes achieved 1-9\% and 4-11\% lower compressive strength than those from conventionalcured concretes at 28 and 90 days of curing, respectively. A lower gain of compressive strength was also showed by steam-cured concretes in accordance with the results reported by various researchers (Kou et al. 2004; Gesoğlu et al. 2013). However, the highest compressive strength gain was achieved by the RCA40 , which indicates that the use of higher porous RCA could contribute to a better binder hydration (Suzuki et al. 2009).

Splitting tensile strength. Table 4 shows the results of splitting tensile strength achieved by all concretes at 28 days. All concrete mixtures, except R60, R40 and R40-SC, achieved the minimum splitting tensile strength required at 28 days by the Spanish technical specification for prestressed concrete sleepers (4.5 MPa) (ADIF 2009).

The concretes produced with RCA100 obtained the highest values due to the influence of its high-quality ITZ between the cement paste and the coarse aggregate (Etxeberria et al. 2007). Concretes produced employing poorer quality RCA achieved lower strength than NAC. The lower quality of the old mortar attached to the RCA and the weaker old ITZ could be responsible for the decrease of splitting tensile strength (Kou et al. 2012).

The use of steam curing process was beneficial for the splitting tensile strength of recycled aggregate concretes. The RACs exposed to steam curing achieved a $4 \%$ higher strength than those concretes exposed to conventional curing process. However, NAC undergoing steam curing achieved lower results than NAC cured on conventional conditions.

Pore structure. The porosity and the average pore diameter obtained by the MIP test at the ages of 1,28 and 90 days are presented in Table 5. Figure 1 shows the cumulative mercury intrusion volume after 1, 28 and 90 days of curing employing both curing methods.

After 1 day of curing, the R100 had significant lower average pore diameters than those of the NAC (Table 5), in both curing methods. Likewise Figure 1a shows that the R100 had slightly lower cumulative intrusion (pore volume) at any pore size than the NAC. Despite the fact that steam curing generally produces larger capillary pores in NAC (Abell et al. 1999), the R100-SC and the R60-SC had finer pore distributions from 1 to $0.05 \mu \mathrm{m}$, but the total cumulative intrusions were similar to those of the NAC-SC. The recycled aggregate concrete produced using RAC sourced from high quality parent concrete (> 60 $\mathrm{MPa}$ ) achieved a lower porosity than those from NAC due to the reduction of the water-cement ratio in the ITZ (Poon, Shui \& Lam 2004) at early hydration. Nevertheless the R40 concretes had the highest pore volume at all pore sizes. After 1 day of curing, the steam-cured concretes obtained lower porosity and average pore diameter than those concretes cured in conventional conditions for a given aggregate type (Table 5 and Figure 1a). The steam curing process enhanced the pozzolanic reactions which led to refinements of the pore structure of the RAC (Berry et al. 1990).

Table 5. Results from MIP tests of the concrete mixtures

\begin{tabular}{|l|c|c|c|c|c|c|}
\hline \multirow{2}{*}{ Mix notation } & \multicolumn{3}{|c|}{ Total Porosity (\%) } & \multicolumn{3}{c|}{ Average pore diameter $(\boldsymbol{\mu m})$} \\
\cline { 2 - 7 } & $\mathbf{1 ~ d a y}$ & $\mathbf{2 8}$ days & $\mathbf{9 0}$ days & $\mathbf{1 ~ d a y}$ & $\mathbf{2 8}$ days & $\mathbf{9 0}$ days \\
\hline NAC & 8.58 & 4.88 & 6.46 & 0.053 & 0.041 & 0.028 \\
\hline R100 & 7.54 & 4.85 & 5.60 & 0.044 & 0.039 & 0.022 \\
\hline R60 & 9.36 & 6.27 & 7.54 & 0.054 & 0.040 & 0.035 \\
\hline R40 & 11.81 & 8.17 & 8.69 & 0.063 & 0.044 & 0.034 \\
\hline \hline NAC-SC & 7.27 & 5.81 & 5.16 & 0.046 & 0.028 & 0.026 \\
\hline R100-SC & 7.36 & 6.02 & 4.71 & 0.039 & 0.034 & 0.023 \\
\hline R60-SC & 7.74 & 6.63 & 5.69 & 0.036 & 0.031 & 0.027 \\
\hline R40-SC & 10.45 & 8.85 & 6.24 & 0.055 & 0.039 & 0.029 \\
\hline
\end{tabular}




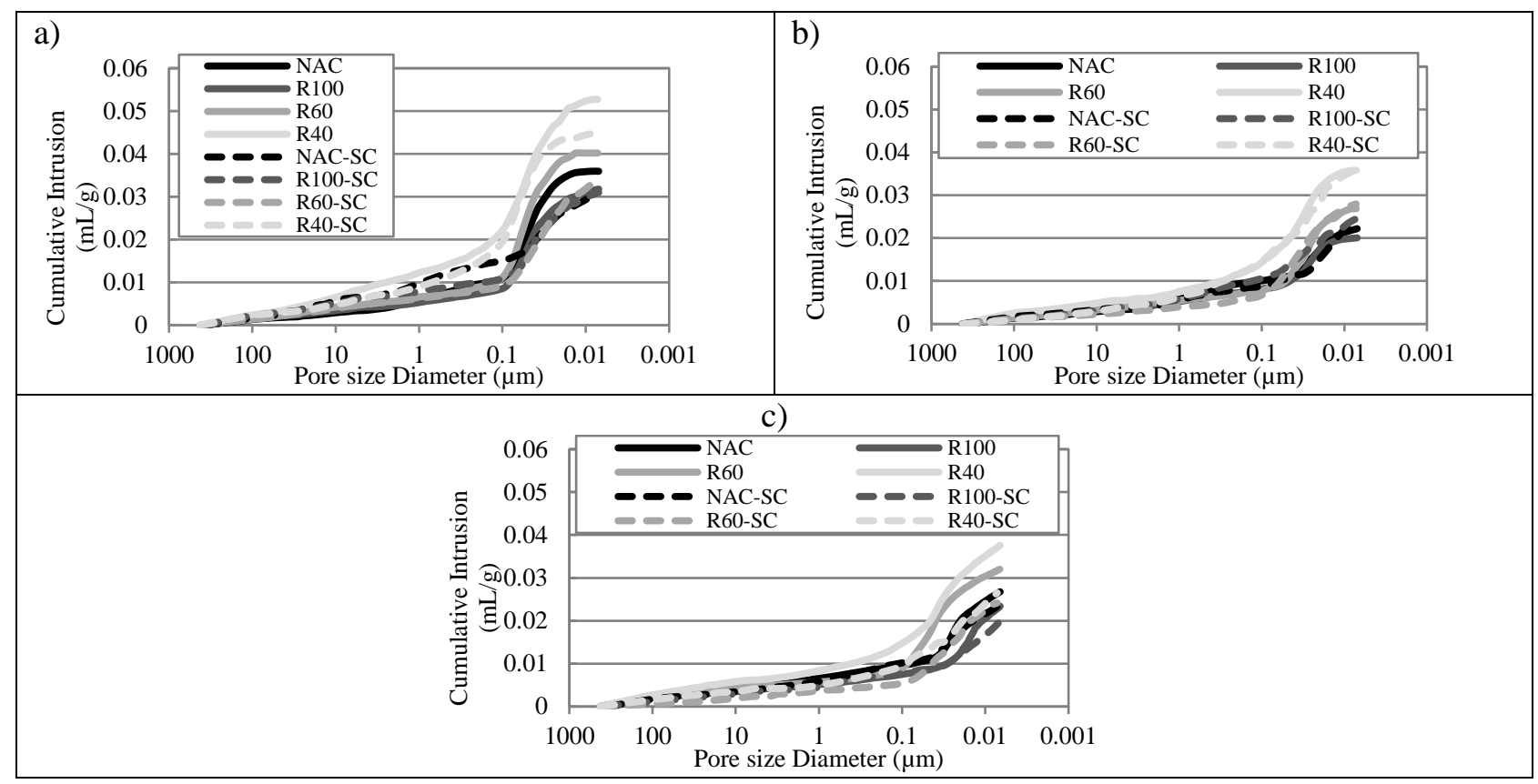

\section{Figure 1. Pore size cumulative distribution of conventional-cured concretes and steam- cured concretes at the ages of 1 day (a), 28 days (b) and 90 days (c)}

At 28 and 90 days of curing, the R100 and the R100-SC had similar or lower average pore diameters than those of the NAC and NAC-SC, respectively. The porosity and the average pore diameter at 28 and 90 days increased with the reduction of the RCA quality, regardless of the curing method used (see Table 5). In line with the findings from some authors (Abell et al. 1999), the average pore sizes results from MIP test were more consistent with those from mechanical and durability properties than total porosities. The total porosities at 28 days showed lower values which could be caused by the misrepresentation of pores volume from typical improper assumptions of MIP method such as "ink bottle" effect (Diamond 2000).

Figs. $1 \mathrm{~b}$ and $1 \mathrm{c}$ show finer pore structure and lower pore volumes of the R100 and R100-SC in comparison with those of the NAC and NAC-SC, respectively. The concretes produced employing the lowest quality RCA had a coarser pore size distribution. However, it must be noted that the steam-cured RAC showed higher reduction (between 16 and 36\%) of the total cumulative intrusion volume from 28 to 90 days in comparison with the NAC (5\%). Probably the higher porosity of the RCA permitted a timeextension of hydration and a more effective water transport through the pore structure (Suzuki et al. 2009). According to the pore size (Mindess \& Young 1981), the RACs showed similar or lower macrocapillary pore volumes than those from the NAC-SC but their meso and microcapillary pore size volumes were similar or slightly higher than those from the NAC-SC. Also pore size distributions revealed that steam-cured concretes had similar distributions even when using medium quality RCA (RCA-40) and that the R100 and the R60 kept lower capillary pore volumes than the NAC after 90 days of curing (Figure 1c).

Water absorption. The NAC achieved the lowest water absorption (see Table 6). The use of 100\% of recycled aggregates significantly increased the water absorption of the recycled aggregates concrete (see Table 6) due to a higher water absorption capacity of RCA (see Table 2) (Gonzalez-Corominas \& Etxeberria 2014). Concretes produced employing RCA100 and RCA40 increased the water absorption capacity in $16-34 \%$ and $82-94 \%$, respectively at 28 days. 
Table 6. Results from the durability properties of concrete

\begin{tabular}{|c|c|c|c|c|c|c|}
\hline \multirow[t]{2}{*}{ Mix notation } & \multicolumn{2}{|c|}{ Water Absorption (\%) } & \multicolumn{2}{|c|}{ Sorptivity $\left(\mathbf{m m} / \mathbf{m i n}^{1 / 2}\right)$} & \multicolumn{2}{|c|}{$\begin{array}{l}\text { Chloride-ion penetration: } \\
\text { Total charge passed }(\mathrm{C})\end{array}$} \\
\hline & 28 days & 180 days & 28 days & 180 days & 28 days & 180 days \\
\hline NAC & 1.96 & 1.49 & 0.011 & 0.008 & 939 & 383 \\
\hline $\mathbf{R} 100$ & 2.63 & 1.66 & 0.009 & 0.008 & 1037 & 338 \\
\hline R60 & 3.17 & 1.80 & 0.031 & 0.007 & 1522 & 676 \\
\hline $\mathbf{R} 40$ & 3.56 & 2.38 & 0.038 & 0.007 & 1804 & 633 \\
\hline NAC-SC & 1.79 & 1.64 & 0.016 & 0.010 & 880 & 457 \\
\hline R100-SC & 2.08 & 2.00 & 0.008 & 0.007 & 811 & 391 \\
\hline R60-SC & 3.07 & 2.02 & 0.028 & 0.007 & 1307 & 714 \\
\hline R40-SC & 3.48 & 2.45 & 0.025 & 0.008 & 1587 & 729 \\
\hline
\end{tabular}

However, the concretes produced with RAC suffered a higher water absorption capacity reduction from 28 to 180 days of curing than those from NAC. In particular, the highest reductions of water absorption capacity and porosity were found in those concretes containing the lowest quality aggregates (RCA60 and RCA 40). The improvement of the long-term physical properties could indicate internal curing effects (Suzuki et al. 2009; Zhutovsky \& Kovler 2012) and beneficial interaction between RCA and fly ash described by several authors (Poon et al. 2000; Yazic1 et al. 2005).

At the age of 28 days, the concretes cured via steam curing achieved slightly lower water absorption capacity than those from conventional-cured concretes. These results are aligned with $\mathrm{Ba}$ et al. (Ba et al. 2011). However, after 180 days, the conventional-cured concretes had higher water absorption improvements which triggered lower values than those from steam curing.

Capillary water absorption. Table 6 shows the results of the sorptivity of the natural and recycled aggregate concretes after 28 and 180 days. After 28 days of curing, the concrete produced with RCA100 achieved the lowest values for both curing methods. However, the use of RCA of a lower quality, RCA60 and RCA40, caused severe increases on its sorptivity due to the high absorption of recycled aggregate and its higher porosity (See Table 2). It has been also reported by others studies (Levy \& Helene 2004; Wirquin et al. 2000).

After 180 days of curing, the concrete containing RCA had similar or lower values to NAC for any concrete series (See Table 6). Particularly, the lower RCA qualities (RCA60 and RCA40) produced highly significant reductions of sorptivity values (68-81\% from 28 to 180 days). The development of the ITZ (Etxeberria et al. 2007; Kou et al. 2012) and the effect of internal curing in concretes (Suzuki et al. 2009; Zhutovsky \& Kovler 2012) containing RCA60 and RCA40 aggregates created improvements on the ITZ and binder matrix to balance the higher porosity of the RCAs.

The comparison of the capillary water absorption of conventional-cured concretes and steam curing concretes for a given aggregate type showed that steam curing had negative effects on NAC (Ba et al. 2011). The conventional-cured NAC had $46.5 \%$ lower sorptivities than those from steam-cured concrete (NAC-SC). In concretes containing RCA, the porous network after steam curing seemed to be improved by an extended binder hydration. The sorptivities of steam-cured RACs were 9-34\% lower than those undergoing conventional curing. 


\section{Chloride-ion penetration}

The results of the resistance to chloride-ion penetration for all concretes at 28 days and 180 days of ages are given in Table 6 . All the concrete mixtures could be classified in the corrosion ranges of very low and low corrosion risk (from ASTM C1202-12) according to their charged passed results.

The concretes containing RCA100 had similar or higher resistance to chloride-ion penetration than those from NAC. The RCA quality drop had detrimental effects on the chloride-ion penetration resistance. However, similarly to the findings from Gesoğlu et al. (Gesoğlu et al. 2013) on lightweight aggregates, the RAC containing fly ash had more similar chloride-ion penetration resistance to those from the reference concrete (NAC) at longer ages.

The use of steam curing for concretes produced using RCA and fly ash increased significantly the chloride-ions penetration resistance of concrete after 28 days. The steam-cured NAC had $6 \%$ lower total amount of charge passed than conventional-cured NAC; while steam-cured concretes with RCA showed 12.0-21.8\% lower charged passed results than conventional-cured RCA concretes. Agreeing with Kou et al. (Kou et al. 2004), the use of steam curing in concretes with recycled aggregates enhanced and accelerated the pozzolanic reaction of fly ash addition. Nevertheless, after 180 days, all the concretes exposed to steam curing showed lower chloride-ion penetration resistance than those concretes exposed to conventional-curing process. However, the negative long-term influence of steam curing was lower in recycled aggregate concretes than in NAC.

\section{CONCLUSIONS}

The following general conclusions can be drawn from the study provided in the paper:

- $\quad$ The concrete produced employing RCA sourced from $100 \mathrm{MPa}$ parent concrete achieved similar or improved mechanical properties, porosity and average pore size than those from NAC. The use of RCA with lower quality cause a reduction of compressive strength and an increase in porosity compared to those from NAC.

- After steam curing process, the concretes produced employing the lowest quality recycled concrete aggregates (sourced from $40 \mathrm{MPa}$ parent concrete) achieved the highest compressive strength evolution from 28 to 90 days, as well as the highest refinement of porous structure.

- The capillary water absorption of concrete with RCA100 was similar or lower than NAC at both testing ages. The use of lower quality RCA negatively influenced the 28-day capillary water absorption, however they had an important reduction from 28 to 180 days. The steam-cured recycled aggregate concretes had similar sorptivity to those from conventional curing at 180 days, however steam-cured NAC had higher sorptivity than conventional-cured NAC.

- The chloride-ion penetration resistance results indicated low corrosion risk even when using

RCA. The steam curing process had low influence on chloride-ion resistivity of concretes, however it was especially positive when concrete mixtures contained RCA.

\section{ACKNOWLEDGEMENT}

The authors wish to acknowledge the financial support of The Ministry of Economy and Competitiveness by INNPACT Project (IPT-2011-1655-370000) and the Hong Kong Polytechnic University.

\section{REFERENCES}

Abell, A.B., Willis, K.L. \& Lange, D.A., 1999. Mercury Intrusion Porosimetry and Image Analysis of Cement-Based Materials. Journal of colloid and interface science, 211(1), pp.39-44. 
ADIF, 2009. Spanish Technical Specifications of Prestressed Concrete Monoblock Sleepers (ET 03.360.571.8), Madrid.

Ajdukiewicz, A. \& Kliszczewicz, A., 2002. Influence of recycled aggregates on mechanical properties of HS/HPC. Cement and Concrete Composites, 24(2), pp.269-279.

$\mathrm{Ba}, \mathrm{M}$. et al., 2011. Effects of steam curing on strength and porous structure of concrete with low water/binder ratio. Construction and Building Materials, 25(1), pp.123-128.

Baoju, L. et al., 2001. Some factors affecting early compressive strength of steam-curing concrete with ultrafine fly ash. Cement and Concrete Research, 31(10), pp.1455-1458.

Berry, E.E., Hemmings, R.T. \& Cornelius, B.J., 1990. Mechanisms of hydration reactions in high volume fly ash pastes and mortars. Cement and Concrete Composites, 12(4), pp.253-261.

Diamond, S., 2000. Mercury porosimetry An inappropriate method for the measurement of pore size distributions in cement-based materials. Cement and Concrete Research, 30, pp.1517-1525.

Etxeberria, M. et al., 2007. Influence of amount of recycled coarse aggregates and production process on properties of recycled aggregate concrete. Cement and Concrete Research, 37(5), pp.735-742.

Eurostat, 2012. Waste statistics in Europe. Available at: http://epp.eurostat.ec.europa.eu/.

Gesoğlu, M. et al., 2013. Strength and transport properties of steam cured and water cured lightweight aggregate concretes. Construction and Building Materials, 49, pp.417-424.

Gonzalez-Corominas, A. \& Etxeberria, M., 2014. Experimental analysis of properties of high performance recycled aggregate concrete. Construction and Building Materials, 52, pp.227-235.

Kou, S., Poon, C. \& Chan, D., 2004. Properties of steam cured recycled aggregate fly ash concrete. In E. Vázquez, C. Hendriks, \& G. Janssen, eds. International RILEM conference on the use of recycled materials in buildings and structures. Barcelona, Spain: RILEM Publications SARL, pp. 590-9.

Kou, S.C. \& Poon, C.S., 2012. Effect of Quality of Parent Concrete on the Mechanical Properties of High Performance Recycled Aggregate Concrete. Journal of chinese ceramic society.

Kou, S.C., Poon, C.S. \& Chan, D., 2008. Influence of fly ash as a cement addition on the properties of recycled aggregate concrete. Materials and Structures, 41(7), pp.1191-201.

Kou, S.C., Poon, C.S. \& Wan, H., 2012. Properties of concrete prepared with low-grade recycled aggregates C \& D Waste. Construction and Building Materials, 36, pp.881-889.

Levy, S.M. \& Helene, P., 2004. Durability of recycled aggregates concrete: a safe way to sustainable development. Cement and Concrete Research, 34(11), pp.1975-1980.

Limbachiya, M., Meddah, M.S. \& Ouchagour, Y., 2011. Use of recycled concrete aggregate in fly-ash concrete. Construction and Building Materials, 27(1), pp.439-449.

Mindess, S. \& Young, J.F., 1981. Concrete, Englewood Cliffs, NJ: Prentice-Hall.

Neville, A.M., 1995. Properties of Concrete 4th ed. Longman, ed.,

Poon, C.S., Shui, Z.H., Lam, L., et al., 2004. Influence of moisture states of natural and recycled aggregates on the slump and compressive strength of concrete. Cement and Concrete Research, 34(1), pp.31-36.

Poon, C.S., Lam, L. \& Wong, Y.L., 2000. A study on high strength concrete prepared with large volumes of low calcium fly ash. Cement and Concrete Research, 30(3), pp.447-455.

Poon, C.S., Shui, Z.H. \& Lam, L., 2004. Effect of microstructure of ITZ on compressive strength of concrete prepared with recycled aggregates. Construction and Building Materials, 18(6), pp.461-468. 
Ramezanianpour, A.A., Khazali, M.H. \& Vosoughi, P., 2013. Effect of steam curing cycles on strength and durability of SCC: A case study in precast concrete. Construction and Building Materials, 49, pp.807-813.

Silva, R.V., De Brito, J. \& Dhir, R.K., 2014. Properties and composition of recycled aggregates from construction and demolition waste suitable for concrete production. Construction and Building Materials, 65, pp.201-217.

Suzuki, M., Seddik Meddah, M. \& Sato, R., 2009. Use of porous ceramic waste aggregates for internal curing of high-performance concrete. Cement and Concrete Research, 39(5), pp.373-381.

Tam, V.W.Y., Gao, X.F. \& Tam, C.M., 2005. Microstructural analysis of recycled aggregate concrete produced from two-stage mixing approach. Cement and Concrete Research, 35(6), pp.1195-1203.

Wirquin, E., Zaharieva, R. \& Buyle-Bodin, F., 2000. Use of water absorption by concrete as a criterion of the durability of concrete - application to recycled aggregate concrete. Materials and Structures, 33, pp.403-8.

Yazicı, H. et al., 2005. Effect of steam curing on class $\mathrm{C}$ high-volume fly ash concrete mixtures. Cement and Concrete Research, 35(6), pp.1122-1127.

Zhutovsky, S. \& Kovler, K., 2012. Effect of internal curing on durability-related properties of high performance concrete. Cement and Concrete Research, 42(1), pp.20-26. 